\title{
Climate impact on Italian fisheries (Mediterranean Sea)
}

\author{
Tomaso Fortibuoni $^{1}$ - Federica Aldighieri ${ }^{2}$ - Otello Giovanardi ${ }^{1} \cdot$ Fabio Pranovi $^{3}$. \\ Matteo Zucchetta ${ }^{3}$
}

Received: 29 January 2015/Accepted: 9 March 2015

(C) Springer-Verlag Berlin Heidelberg 2015

\begin{abstract}
Global warming is increasingly affecting marine ecosystems and ecological services they provide. One of the major consequences is a shift in species geographical distribution, which may affect resources availability to fisheries. We computed the mean temperature of the catch (MTC) for Italian catches from 1972 to 2012 to test if an increase of warmer-water species against colder-water ones was observed. We further analysed the relationship among MTC, landings, fishing effort and climatic factors through
\end{abstract}

Editor: Wolfgang Cramer.

Electronic supplementary material The online version of this article (doi:10.1007/s10113-015-0781-6) contains supplementary material, which is available to authorized users.

Tomaso Fortibuoni

tomaso.fortibuoni@isprambiente.it

Federica Aldighieri

federica.aldighieri@isprambiente.it

Otello Giovanardi

otello.giovanardi@isprambiente.it

Fabio Pranovi

fpranovi@unive.it

Matteo Zucchetta

matzuc@unive.it

1 The Italian National Institute for Environmental Protection and Research (ISPRA), Loc. Brondolo, Chioggia, 30015 Venice, Italy

2 The Italian National Institute for Environmental Protection and Research (ISPRA), Via Vitaliano Brancati 60, 00144 Rome, Italy

3 Department of Environmental Sciences, Informatics and Statistics, CEMAS-Centre for Estuarine and coastal Marine Sciences, University Ca' Foscari of Venice, Campus scientifico, Via Torino 150, 30170 Venice, Italy a Linear Mixed Models approach. Global MTC increased at a rate of $0.12{ }^{\circ} \mathrm{C}$ per decade. Though, by considering the influence of sea surface temperature (SST), a strongest increase $\left(0.31^{\circ} \mathrm{C}\right)$ was estimated in southernmost areas, while in the northernmost basin (Northern Adriatic Sea) a decrease of $0.14{ }^{\circ} \mathrm{C}$ was observed. SST resulted the most relevant driver, and the relationship between MTC and SST showed a high spatial variability both in terms of strength and sign, being positively stronger in southernmost areas while negative in the northernmost basin. The result is probably underestimated since several psychrophilous and thermophilous species were not included in the analysis. However, it seems that a change towards warmer-water species has already occurred in Italian marine ecosystems. Conversely, total landings temporal dynamics seem mostly driven by changes in fishing effort rather than by MTC and climatic factors. Consequently, fishery management strategies need to focalize primarily on fishing effort reduction, in order to reduce the pressure on the stocks while increasing their resilience to other stressors, among which global warming.

Keywords Climate change $\cdot$ MTC $\cdot$ SST $\cdot$ NAO $\cdot$ Linear Mixed Models $\cdot$ Mediterranean Sea

\section{Introduction}

Climate variability has always occurred throughout geological times and ecosystems have evolved consequently. However, the actual rate of climate change is more rapid than previous natural changes (Brander 2013), human influence on the climate system is clear (IPCC 2013), and the resilience of species and systems has being already compromised by concurrent pressures (Brander 2010). As a 
result, ocean warming is currently considered one of the main driving forces causing changes in the marine communities' structure (Portner and Peck 2010).

These changes affect marine species in terms of distribution shifts, growth rates, spawning period, size at maturity, recruitment and mortality (Pecl et al. 2014). Thus, such changes are expected to affect ecosystem services (e.g. fisheries; Gamito et al. 2015) all around the world. In particular, the vulnerability of a fishery to climate depends on induced changes in fish stocks that affect species composition and thus abundance in commercial catches. Fisheries should be affected by "meridionalization" (Azzurro et al. 2011) and "tropicalization" (Bianchi 2007) of catch, i.e. an increase of warmer-water species in relation to colder-water ones, since shifts in distribution are expected to affect their availability to fisheries (Rijnsdorp et al. 2009; Cheung et al. 2013). Landings may change in relation to global warming (Teixeira et al. 2014), and this may induce changes in the intensity and spatial distribution of fishing effort (Haynie and Pfeiffer 2012). The exposure of a fishing community will be greatest where other pressures, such as overfishing, are already stressing the socialecological system (Miller et al. 2010). Also fish stocks, if already overexploited, are more strongly affected by climate change. This is due to reduced age structure, restriction of geographic distribution, loss of diversity etc. (Rijnsdorp et al. 2009; Perry et al. 2010; Planque et al. 2010).

Unfortunately, most of the Mediterranean fish stocks are currently overexploited (Colloca et al. 2011), making them particularly vulnerable to climate change, as observed, for instance, for the Northern Adriatic Sea (Pranovi et al. 2013). In that fishery, commercial catch is entirely composed of species from cold and temperate latitudes that have decreased during the past decade as a consequence of global warming.

Each species has individual characteristics which govern responses to environmental changes, thus the complexity of these processes and their interaction makes the task of understanding and predicting the impacts of climate on fisheries production tricky (Brander 2010). One possible solution is to look at the behaviour at a higher level, for instance community. We applied the mean temperature of the catch (MTC) index (Cheung et al. 2013) to Italian landings for the period 1972-2012 to test if an increase of warmer-water species against colder-water ones was observed. In order to disentangle the role of different driving forces on MTC changes, we used Linear Mixed Models (LMM) with an ensemble of different combination of predictors, i.e. the mean sea surface temperature (SST), the North Atlantic Oscillation index (NAO), landings and fishing effort. Moreover, we investigated if total landings are actually quantitatively affected by MTC dynamics, since climate and exploitation may likely interact in their effects (Planque et al. 2010).

In particular, the aims of this study were to analyze MTC temporal changes in different areas belonging to Italian seas in relation to climatic factors and fishing effort, and to investigate how changes in MTC contributed, in space and time, to changes in landings.

\section{Materials and methods}

\section{Landings and mean temperature of the catch}

Annual landings (1972-2012) originated from official Italian statistics on fishery, reported by the Italian National Institute of Statistics (ISTAT) from 1972 to 2004, and by the Institute for Economic Research in Fishery and Aquaculture (IREPA) from 2005 to 2012.

Landings were expressed in terms of species or groups of species wet weight $(\mathrm{kg} /$ year) per region, and do not include discarded, illegal and unreported catches. To take into account possible geographical differences in variables relationships and trends, regional data were grouped in six areas (Fig. 1).

The taxonomic resolution of landings changed over time, so only species clearly recognizable across the entire time-series were included in the analysis. The final database resulted to be composed by 25 species in each region (35 species in total, since some species were different according to the region). For each species the thermal preference (median temperature preference, $T$ ) was assigned according to Cheung et al. 2013 (Table S1).

The yearly MTC was calculated for each region from the average inferred temperature preference of exploited species, weighted by their annual landing (Cheung et al. 2013), according to the following formula:

$\mathrm{MTC}_{\mathrm{yr}}=\sum_{i}^{n} c_{i, \mathrm{yr}} \cdot T_{i} / \sum_{i}^{n} c_{i, \mathrm{yr}}$

where $c_{i, \mathrm{yr}}$ is the landing of species $i$ in a specific region in year $\mathrm{yr}, T_{i}$ is the median temperature preference of species $i$ and $n$ is the total number of species.

\section{Trawl-survey data}

Biomass data were obtained from the Mediterranean International Trawl Survey program (MEDITS) for the years 1994-2011 (for further details see Bertrand et al. 2002). These data were used to calculate the MTC in the FAO Geographical Sub Area 17 (GSA 17, corresponding to Area 1 and 2 in Fig. 1) for the period 1994-2011 to test the effect of the use of landings or survey data in estimating 
Fig. 1 The area of study. Dashed lines indicate different areas into which regional landings were grouped

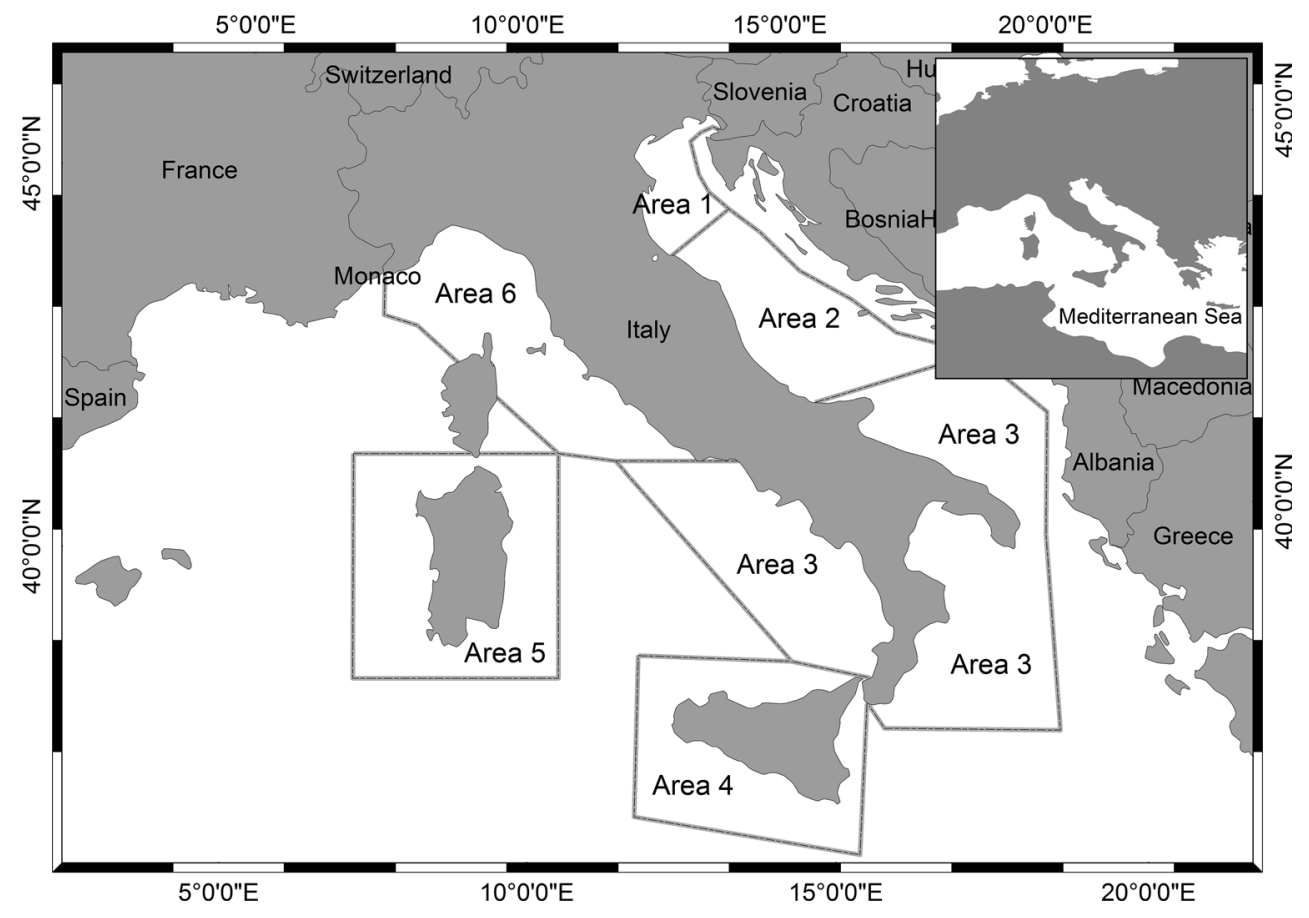

The structure (i.e. the included predictors) of the models has been chosen evaluating different alternative combinations of formulations (Table S2). Model 1 uses MTC as response variable and year, fishing effort, SST and NAO as candidate predictors; Model 2 relates landings (response variable) to the same predictors of the first model; Model 3 is fitted to explore the role of MTC in influencing landings, and it considers landings as the response variable, the optimal structure - as defined by the model selection procedure-of Model 2 and MTC as candidate variables.

Different alternative correlations terms and random structures were evaluated following the protocol proposed by Zuur et al. (2009). After the choice of the optimal random structure, alternative formulations of the fixed part were fitted to explore different combinations of explanatory variables (see Table S2). The optimal structure of models was evaluated considering the Akaike Information Criterion, corrected for small samples (AICc; Grueber et al. 2011). In case of no strong support for one single 'best' model ( $\triangle \mathrm{AICc}$ smaller than four for the two models with the lower AICc values), inferences were carried out on an averaged model, built computing the weighted averages parameters for each independent variable, using AICc weights $\left(\mathrm{W}_{\mathrm{AICc}}\right)$ (Burnham and Anderson 2002, Burnham et al. 2011) and considering the set of models whose cumulative weights $\left(\mathrm{W}_{\mathrm{AICc}}\right)$ represent $95 \%$ of the total ensemble. Calculations were carried out using the 'nlme' (model fitting; Pinhero and Bates 2000) and 'MuMIn' (model averaging; Barton 2014) packages, within the $\mathrm{R}$ statistical environment (v. 2.15.1; R Core Team 2012).
A LMM approach (Pinhero and Bates 2000) was followed to assess the relationship among MTC, landings, fishing effort and climatic factors, fitting three models by using different response variables, namely MTC and landings. 


\section{Results}

No significant difference $(F=2.634, p=0.1144)$ was found between using landings and scientific bottom trawl survey data in the rate of change in MTC in GSA 17.

The optimal structure for the LMM for MTC includes an autoregressive correlation structure (AR1) and a structure that allows a different variance for each region, in order to address to heteroschedasticity issues. The temporal correlation between years is high $(\mathrm{phi}=0.76)$, and it is not possible to estimate a unique optimal structure of the fixed part, following the AICc criterion. The average model, obtained by using the three models, suggested the presence of a linear trend of MTC over time, with an increase rate of $0.12{ }^{\circ} \mathrm{C}$ per decade and an area-specific dependence of MTC from SST. This means that changes of MTC over time are composed by a fixed rate $\left(0.12{ }^{\circ} \mathrm{C} \times 10\right.$ year $\left.^{-1}\right)$ plus a variable part that depends from the rate of change of SST in each area (Table 1). The relationship follows a latitudinal gradient, being strongest for Area 4 (Table 1) and increasingly weaker moving northward, with the Northern Adriatic area (Area 1) showing a negative relationship (i.e. MTC decreases with increasing water temperatures). Moreover, a high heterogeneity in terms of dependence of MTC from SST trend was observed among areas.

The model developed for landings has a different random structure, including a random intercept for the factor Area, in addition to the components already present in Model 1. The temporal correlation between years is stronger ( $\mathrm{phi}=0.85$ ) than for MTC, and the uncertainty in the selection of the fixed structure is higher $(\triangle \mathrm{AICc}$ among models is generally lower, and the average model was fitted considering 12 different models). There is a positive trend in landings, but the temporal dynamic is less strong than for MTC. The most influential variables are fishing effort, positively correlated with landings, and NAO, negatively correlated with landings. The dependence from SST is less important than for MTC, and it changes in the different areas. Specifically, this relationship is notably stronger in the southernmost area (Area 4; Table 1).

To understand the effects over time on landings of changes in MTC, a new set of models was considered: this is composed by the 12 models considered after the selection procedure for Model 2 (same fixed and random structure) and 12 additional models with the same random structure and considering the same covariates, but including also MTC among the predictors. The model selection procedure indicates that uncertainty increases, and the best combination of models is obtained considering 18 models, mixing some of the models including MTC with some models without this term among the predictors (Table S2). The role of the other variables are similar as for Model 2 (even if NAO is the most influential variable), and MTC is positively correlated with landings, even if it represents the less important variable and seems to contribute marginally on the prediction of landings (Table 1).

\section{Discussion}

Within the context of the Mediterranean basin, the Italian Seas can be considered an interesting case study to analyze possible effects of climate changes on fish communities and fisheries, due to the presence of a high environmental variability and a wide latitudinal gradient. The different

Table 1 Estimated parameters of the models

\begin{tabular}{|c|c|c|c|c|c|c|c|c|c|}
\hline & \multicolumn{3}{|c|}{ Model for MTC } & \multicolumn{3}{|c|}{ Model for landings } & \multicolumn{3}{|c|}{ Model for landings (including MTC) } \\
\hline & Estimate & $\begin{array}{l}\text { Adjusted } \\
\text { st. error }\end{array}$ & $\begin{array}{l}\text { AICc } \\
\text { weigths }\end{array}$ & Estimate & $\begin{array}{l}\text { Adjusted } \\
\text { st. error }\end{array}$ & $\begin{array}{l}\text { AICc } \\
\text { weigths }\end{array}$ & Estimate & $\begin{array}{l}\text { Adjusted } \\
\text { st. error }\end{array}$ & AICc weigths \\
\hline Intercept & -4.477 & 7.459 & - & $57,650.88$ & $219,402.60$ & - & $50,063.78$ & $221,098.48$ & - \\
\hline $\mathrm{kW}$ & 0.000 & 0.000 & 0.262 & 0.14 & 0.07 & 0.72 & 0.14 & 0.07 & 0.73 \\
\hline SST & - & - & - & 561.19 & 344.15 & 0.53 & 552.20 & 340.62 & 0.52 \\
\hline YEAR & 0.012 & 0.004 & 1.000 & 13.61 & 180.80 & 0.37 & 12.01 & 180.27 & 0.37 \\
\hline NAO & -0.002 & 0.006 & 0.194 & -369.23 & 154.90 & 0.69 & -375.64 & 153.75 & 0.74 \\
\hline Area 4:SST & 0.019 & 0.015 & 1.000 & $10,462.14$ & 3571.00 & 0.34 & $10,455.39$ & 3570.29 & 0.35 \\
\hline Area 6:SST & 0.015 & 0.014 & & -194.61 & 1391.88 & & -196.29 & 1388.17 & \\
\hline Area 5:SST & 0.017 & 0.021 & & -274.45 & 1830.87 & & -317.88 & 1824.86 & \\
\hline Area 1:SST & -0.026 & 0.014 & & 1449.23 & 1050.28 & & 1446.96 & 1045.29 & \\
\hline Area 2:SST & 0.002 & 0.013 & & 572.58 & 372.25 & & 554.93 & 368.33 & \\
\hline Area 3:SST & 0.019 & 0.013 & & 136.23 & 1015.35 & & 121.45 & 1016.53 & \\
\hline MTC & - & - & - & - & - & - & 1090.49 & 1043.85 & 0.33 \\
\hline
\end{tabular}

The estimation refers to the averaged models 
areas surrounding the Italian peninsula and its isles are characterized, indeed, by different features, such as water temperature, hydrodynamic circulation, nutrients load, that all directly affect marine communities (Cataudella and Spagnolo 2011).

Although we are aware of the limitations inherent in the use of commercial data to infer changes at community level, MTC confirmed to be a robust proxy to examine changes in relation to ocean warming (Cheung et al. 2013), since the rate of change does not depend on the type of data used. Indeed, no significant difference was found between using landings and scientific bottom trawl survey data in the MTC rate of change.

Globally, the MTC in Italian waters increased at a rate of $0.12{ }^{\circ} \mathrm{C}$ per decade in the last 40 years, without considering the effect of SST. Thus, an increasing dominance of catches of warm affinity species occurred in the landings. This value resulted lower than those reported for the Western and Central Mediterranean $\left(0.56\right.$ and $1.05{ }^{\circ} \mathrm{C}$ per decade, respectively) by Tsikliras and Stergiou (2014), but more similar to that reported for the Greek Seas $\left(0.16{ }^{\circ} \mathrm{C}\right.$ per decade) (Tsikliras and Stergiou 2013). These differences may derive from the different spatial scale at which MTC changes are analyzed in these works, but are also strongly influenced by the relationship with SST. Indeed, our model formulation considers also the influence of temperature whose signal should be added to the $0.12{ }^{\circ} \mathrm{C}$ rate of change. For instance, if we consider also SST effect the strongest increase of MTC was estimated $\left(0.31^{\circ} \mathrm{C}\right.$ per decade and per ${ }^{\circ} \mathrm{C}$ of increase of SST) in southernmost areas (3 and 4), while in the northernmost basin (Area 1) a decrease of $0.14{ }^{\circ} \mathrm{C}$ (per decade and per ${ }^{\circ} \mathrm{C}$ of increase of SST) was estimated. In general, SST resulted the most influential variable in driving MTC temporal changes. This is not surprising, since temperature is recognized to be the main driving force causing shifts in the geographical distribution of species (Ben Rais Lasram et al. 2010; Portner and Peck 2010; Cheung et al. 2013; Tsikliras and Stergiou 2014).

It is worth noting that, while the signal is well-defined, our result is rather conservative, given that several thermophilous species (e.g. Lessepsian migrants) and psychrophilous species (Atlantic relicts, such as Platichthys flesus and Sprattus sprattus) were not included in the analysis, since their catches were not recorded in available statistics. This means that probably the rate of warminginduced changes is higher than that here reported, as observed also by other authors (Tsikliras and Stergiou 2014).

The relationship between MTC and SST, even if significant in each of the analyzed areas, showed a high spatial variability both in terms of strength and sign. This could be related to the local environmental features characterizing each area and the structure of underlying communities. For example Area 4 (Sicilian Seas), due to its peculiar hydrodynamic conditions and being at the boundary between the West and East Mediterranean, is recognized as one of the most influenced by/exposed to climate change (Gasparini et al. 2005). In this area, the MTC-SST relationship revealed to be the strongest positive one. On the opposite, in the Northern Adriatic Sea (Area 1) a negative MTC-SST relationship was detected. The Northern Adriatic Sea is one of the coldest Mediterranean basins, hosting an endemic community mainly composed by cold/temperate affinity species (Pranovi et al. 2013). Within this context of 'low' temperature, the water warming is expected to, at least during a first phase, positively affect the biological cycles of endemic species, increasing their production (NormanLópez et al. 2013). Thus, the Northern Adriatic Sea may be acting as a refuge for cold-water species (Ben Rais Lasram et al. 2010). This hypothesis is supported also by the positive relation between SST and landings in the area. However, in the long-term the area may become a 'cul-desac' for such species (Ben Rais Lasram et al. 2010), since Mediterranean surface waters are expected to warm by an average of $3.1{ }^{\circ} \mathrm{C}$ by the end of the twentyfirst century (Somot et al. 2006). A warming that exceeds the thermal tolerance of psychrophilous species may negatively impact catch potential in the region, with direct implications for fishing communities.

Conversely, the temporal trend resulted to be less important for landings, being the fishing effort the most important explaining variable. In general, the SST seems to play a less important role in affecting landings trend. However, significant differences among areas have been recorded, with a higher positive impact of warming in Area 4 , suggesting that the increase in water temperature favoured fishery in the last 40 years, and confirming the hypothesis of a stronger effect on southernmost areas.

On the other hand, NAO's role in determining MTC and landings trends resulted to be marginal and highly variable depending on the area. This result confirms that, even if it was expected the NAO to influence marine communities (Conversi et al. 2010), the effects on Mediterranean meteorological/climatic conditions are weak and sometimes controversial (Lionello and Galati 2008; Vicente-Serrano and Trigo 2011).

Finally, MTC resulted to be scarcely related to landings in all areas. This could mean that, even if in presence of clear changes in fish community structure due to ocean warming, actually such modifications do not deeply modify fishing activities.

In conclusion, MTC confirmed to be a good aggregated index useful to describe the effects of climate change on marine communities and fisheries. Thus, the index should be adopted to monitor how global warming is affecting marine ecosystem services in the framework of the EU 
Strategy on adaptation to climate change. It is worth noting that the spatial scale of analysis plays a crucial role in determining the outputs, both in terms of the increasing rate and sign of the interaction with SST. However, the presence of a weak relationship between MTC and landings suggests that, at present, MTC cannot be used to inform fishery management strategies. Within the context of a general trend of change driven by increasing temperature, landings are mainly affected by other drivers, first of all fishing effort. Therefore, in order to cope with the effects of climate change, fishery management strategies need to focalize primarily on fishing effort reduction, in order to reduce the pressure on the stocks while increasing their resilience to other stressors, like global warming.

Acknowledgments We acknowledge M. Gambino and L. Labanchi for providing landing and fishing effort data, the Italian Ministry of Agricultural, Food and Forestry Policies for granting permission to use MEDITS data. We also thank V. Meccia for preparing and providing data of SST and NAO. The study benefited from discussions with colleagues of the ICES Working Group on the History of Fish and Fisheries, who are warmly thanked.

\section{References}

Anticamara JA, Watson R, Gelchu A, Pauly D (2011) Global fishing effort (1950-2010): trends, gaps, and implications. Fish Res 107:131-136. doi:10.1016/j.fishres.2010.10.016

Azzurro E, Moschella P, Maynou F (2011) Tracking signals of change in Mediterranean fish diversity based on local ecological knowledge. PLoS ONE 6(9):e24885. doi:10.1371/journal.pone. 0024885

Barton K (2014) MuMIn: multi-model inference. R package version. 1.10.5. http://CRAN.R-project.org/package=MuMIn. Accessed 20 December 2014

Ben Rais Lasram F, Guilhaumon F, Albouy C, Somot S, Thuiller W, Mouillot D (2010) The Mediterranean Sea as a 'cul-de-sac' for endemic fishes facing climate change. Glob Change Biol 16:3233-3245. doi:10.1111/j.1365-2486.2010.02224.x

Bertrand JA, Gil de Sola L, Papaconstantinou C, Relini G, Souplet A (2002) The general specifications of the MEDITS surveys. Sci Mar 66:9-17

Bianchi CN (2007) Biodiversity issues for the forthcoming tropical Mediterranean Sea. Hydrobiologia 580:7-21. doi:10.1007/9781-4020-6156-1_1

Brander K (2010) Impacts of climate change on fisheries. J Mar Syst 79:389-402. doi:10.1016/j.jmarsys.2008.12.015

Brander K (2013) Climate and current anthropogenic impacts on fisheries. Clim Change 119:9-21. doi:10.1007/s10584-012-05412

Burnham KP, Anderson DR (2002) Model selection and multimodel inference: a practical information-theoretic approach, 2nd edn. Springer, Berlin

Burnham KP, Anderson DR, Huyvaert KP (2011) AIC model selection and multimodel inference in behavioral ecology: some background, observations, and comparisons. Behav Ecol Sociobiol 65(1):23-35. doi:10.1007/s00265-010-1029-6
Cataudella S, Spagnolo M (2011) The state of Italian marine fisheries and aquaculture. Ministero delle Politiche Agricole, Alimentari e Forestali, Rome

Cheung WWL, Watson R, Pauly D (2013) Signature of ocean warming in global fisheries catch. Nature 497:365-369. doi:10. 1038/nature 12156

Colloca F, Cardinale M, Giannoulaki M, Scarcella G, Jenko K, Fiorentino F, Bellido JM, Maynou F (2011) Rebuilding Mediterranean fisheries: toward a new paradigm for ecological sustainability in single species population models. Fish Fish 14:89-109. doi:10.1111/j.1467-2979.2011.00453.x

Conversi A, Fonda Umani S, Peluso T, Molinero JC, Santojanni A, Edwards M (2010) The Mediterranean sea regime shift at the end of the 1980s, and intriguing parallelisms with other European basins. PLoS ONE 5(5):e10633. doi:10.1371/journal.pone. 0010633

Gamito R, Costa MJ, Cabral HN (2015) Fisheries in a warming ocean: trends in fish catches in the large marine ecosystems of the world. Reg Environ Change 15:57-65. doi:10.1007/s10113-0140615-y

Gasparini GP, Ortona A, Budillon G, Astraldi M, Sansone E (2005) The effect of the Eastern Mediterranean Transient on the hydrographic characteristics in the Strait of Sicily and in the Tyrrhenian Sea. Deep-Sea Res I 52:915-935

Grueber CE, Nakagawa S, Laws RJ, Jamieson IG (2011) Multimodel inference in ecology and evolution: challenges and solutions. J Evolut Biol 24(4):699-711. doi:10.1111/j.1420-9101.2010. 02210.x

Haynie AC, Pfeiffer L (2012) Why economics matters for understanding the effects of climate change on fisheries. ICES J Mar Sci 69(7):1160-1167. doi:10.1093/icesjms/fss021

Hurrell J et al. (2014) The Climate Data Guide: Hurrell North Atlantic Oscillation (NAO) Index (station-based). https://climatedata guide.ucar.edu/climate-data/hurrell-north-atlantic-oscillationnao-index-station-based. Accessed 25 January 2014

IPCC (2013) Summary for Policymakers. In: Stocker TF, Qin D, Plattner GK, Tignor M, Allen SK, Boschung J, Nauels A, Xia Y, Bex V, Midgley PM (eds) Climate change 2013: the physical science basis. Contribution of working group I to the fifth assessment report of the intergovernmental panel on climate change. Cambridge University Press, Cambridge, pp 4-29

Lionello P, Galati MB (2008) Links of the significant wave height distribution in the Mediterranean Sea with the Northern Hemisphere teleconnection patterns. Adv Geosci 17:13-18. doi:10. 5194/adgeo-17-13-2008

Miller K, Charles A, Barange M, Brander K, Gallucci VF, Gasalla MA, Khan A, Munro G, Murtugudde R, Ommer RE, Perry RI (2010) Climate change, uncertainty, and resilient fisheries: institutional responses through integrative science. Prog Oceanogr 87:338-346. doi:10.1016/j.pocean.2010.09.014

Norman-López A, Plagányi E, Skewes T, Poloczanska E, Dennis D, Gibbs M, Bayliss P (2013) Linking physiological, population and socio-economic assessments of climate-change impacts on fisheries. Fish Res 148:18-26

Pecl GT, Ward TM, Doubleday ZO, Clarke S, Day J, Dixon C, Frusher S, Gibbs P, Hobday AJ, Hutchinson N, Jennings S, Jones K, Li X, Spooner D, Stoklosa R (2014) Rapid assessment of fisheries species sensitivity to climate change. Clim Change 127:505-520. doi:10.1007/s10584-014-1284-z

Perry RI, Cury P, Brander K, Jenning S, Möllmann C, Planque B (2010) Sensitivity of marine systems to climate and fishing: concepts, issues and management responses. J Mar Syst 79:427-435. doi:10.1016/j.jmarsys.2008.12.017

Pinhero JC, Bates DM (2000) Mixed-effects models in $S$ and S-PLUS. Springer, New York 
Planque B, Fromentin JM, Cury P, Drinkwater JF, Jennings S, Perry RI, Kifani S (2010) How does fishing alter marine populations and ecosystems sensitivity to climate? J Mar Syst 79:403-417. doi:10.1016/j.jmarsys.2008.12.018

Portner HO, Peck MA (2010) Climate change effects on fishes and fisheries: towards a cause-and-effect understanding. J Fish Biol 77(8):1745-1779. doi:10.1111/j.1095-8649.2010.02783.x

Pranovi F, Caccin A, Franzoi P, Malavasi S, Zucchetta M, Torricelli P (2013) Vulnerability of artisanal fisheries to climate change in the Venice Lagoon. J Fish Biol 83(4):847-864. doi:10.1111/jfb. 12124

R Core Team (2012) R: a language and environment for statistical computing. $\mathrm{R}$ foundation for statistical computing, Vienna, Austria, http://www.R-project.org/

Rijnsdorp AD, Peck MA, Engelhard GH, Möllmann C, Pinnegar JK (2009) Resolving the effect of climate change on fish populations. ICES J Mar Sci 66:1570-1583. doi:10.1093/icesjms/ fsp056

Somot S, Sevault F, Déqúe M (2006) Transient climate change scenario simulation of the Mediterranean Sea for the twenty-first century using a high-resolution ocean circulation model. Clim Dyn 27:851-879. doi:10.1007/s00382-006-0167-z

Teixeira CM, Gamito R, Leitão F, Cabral HN, Erzini K, Costa MJ (2014) Trends in landings of fish species potentially affected by climate change in Portuguese fisheries. Reg Environ Change 14:657-669. doi:10.1007/s10113-013-0524-5

Tsikliras AC, Stergiou KI (2013) Mean temperature of the catch from the Greek Seas. Proc Hell Conf Ichthyol 15:205-208

Tsikliras AC, Stergiou KI (2014) Mean temperature of the catch increases quickly in the Mediterranean Sea. Mar Ecol Prog Ser 515:281-284. doi:10.3354/meps11005

Vicente-Serrano SM, Trigo RM (2011) Hydrological, socioeconomic and ecological impacts of the North Atlantic Oscillation in the Mediterranean region. Springer, Houten

Zuur AF, Ieno EN, Walker NJ, Saveliev AA, Smith GM (2009) Mixed effects models and extensions in ecology with R, statistics for biology and health, statistics for biology and health. Springer, New York. doi:10.1007/978-0-387-87458-6 